\title{
Myosinopathies: pathology and mechanisms
}

\author{
Homa Tajsharghi $\cdot$ Anders Oldfors
}

Received: 10 April 2012/Revised: 27 June 2012/Accepted: 19 July 2012 / Published online: 5 August 2012

(C) The Author(s) 2012. This article is published with open access at Springerlink.com

\begin{abstract}
The myosin heavy chain (MyHC) is the molecular motor of muscle and forms the backbone of the sarcomere thick filaments. Different MyHC isoforms are of importance for the physiological properties of different muscle fiber types. Hereditary myosin myopathies have emerged as an important group of diseases with variable clinical and morphological expression depending on the mutated isoform and type and location of the mutation. Dominant mutations in developmental MyHC isoform genes (MYH3 and MYH8) are associated with distal arthrogryposis syndromes. Dominant or recessive mutations affecting the type IIa MyHC (MYH2) are associated with early-onset myopathies with variable muscle weakness and ophthalmoplegia as a consistent finding. Myopathies with scapuloperoneal, distal or limb-girdle muscle weakness including entities, such as myosin storage myopathy and Laing distal myopathy are the result of usually dominant mutations in the gene for slow/ $\beta$ cardiac MyHC (MYH7). Protein aggregation is part of the features in some of these myopathies. In myosin storage myopathy protein aggregates are formed by accumulation of myosin beneath the sarcolemma and between myofibrils. In vitro studies on the effects of different mutations associated with myosin storage myopathy and Laing distal myopathy indicate altered biochemical and biophysical properties of the light meromyosin, which is essential for thick filament assembly. Protein aggregates in the form of tubulofilamentous inclusions in association with vacuolated muscle fibers are
\end{abstract}

H. Tajsharghi · A. Oldfors $(\square)$

Department of Pathology, Institute of Biomedicine,

University of Gothenburg, Sahlgrenska University Hospital,

41345 Gothenburg, Sweden

e-mail: anders.oldfors@gu.se present at late stage of dominant myosin IIa myopathy and sometimes in Laing distal myopathy. These protein aggregates exhibit features indicating defective degradation of misfolded proteins. In addition to protein aggregation and muscle fiber degeneration some of the myosin mutations cause functional impairment of the molecular motor adding to the pathogenesis of myosinopathies.

Keywords Myopathy - Myosin - Myosin heavy chain · Mutation - Myosin storage myopathy .

Laing distal myopathy · Protein aggregate

\section{Introduction}

Myosin is a highly conserved, ubiquitous protein found in all eukaryotic cells [57]. It acts as a molecular motor that converts chemical energy of ATP hydrolysis into mechanical force for diverse cellular movements such as cytokinesis, phagocytosis, and muscle contraction [58]. Myosins constitute a diverse superfamily and are grouped into different classes including the conventional, or class II, two-headed myosins that form filaments in striated muscle, smooth muscle and non-muscle cells [64]. The class II conventional muscle myosin exists as a hexameric protein composed of two myosin heavy chain (MyHC) subunits and two pairs of non-identical light chain subunits [57, 64]. MyHCs associate into dimers through a coiled-coil interaction along its long tail, which is termed the rod domain (Fig. 1). Dimerization of two heavy chains results in a polar structure with two distinct regions, which provide the motor and filament-forming functions. The amino terminus forms a globular head domain that binds to actin and ATP, which is required for motor activity [56]. The elongated $\alpha$-helical coiled-coil C-terminal rod domain exhibits 

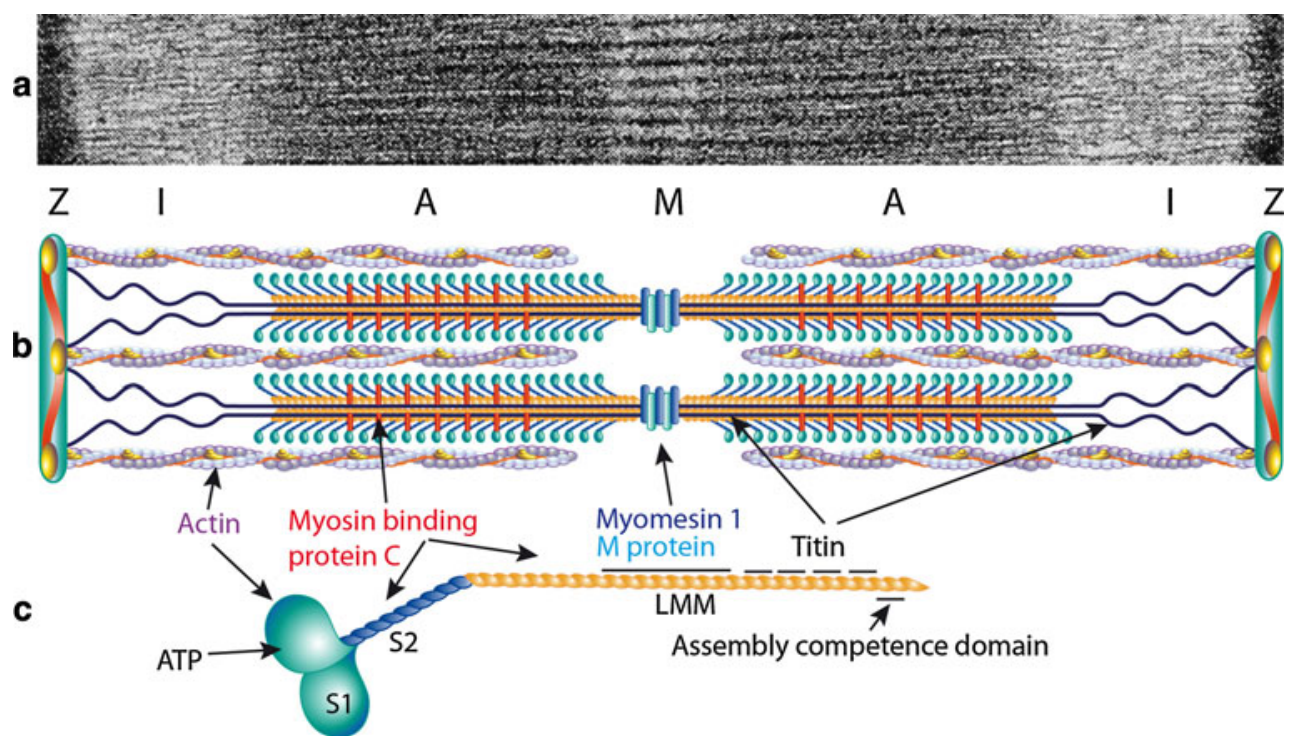

Fig. 1 a Electron micrograph of a skeletal muscle sarcomere, demonstrating thick and thin filaments and the banding pattern. b Schematic drawing of the sarcomere demonstrating the thin filaments composed mainly of actin, tropomyosin and the troponin complex and the thick filaments composed mainly of myosin with the myosin heavy chain (MyHC) globular heads interacting with the thin

filament-forming properties that assemble into thick filaments of the sarcomeres (Fig. 1) [57].

Mutations in MyHC genes have been demonstrated to be an important cause of various myopathies, some of which are associated with protein aggregates in muscle fibers $[49,50]$.

\section{Myosin heavy chain isoforms}

There are several striated muscle MyHC isoforms encoded by different genes and expressed in a tissue and developmental specific manner [61-63, 84, 85]. In adult human limb skeletal muscle there are three major MyHC isoforms: MyHC I, also called slow/ß-cardiac MyHC, is encoded by MYH7 and is expressed in slow, type 1 muscle fibers as well as in the ventricles of the heart; MyHC IIa (MYH2) is expressed in fast, type 2A muscle fibers and MyHC IIx $(M Y H 1)$ is expressed in fast, type 2B muscle fibers [66] (Table 1). The three different muscle fiber types differ in their contractile and physiological properties, which are partly determined by the different MyHCs. In addition, embryonic and perinatal MyHCs, encoded by $M Y H 3$ and MYH8, are expressed during fetal development and also during muscle regeneration [24, 31].

In addition to the common MyHC isoforms expressed in fibers of adult human limb muscles, there are special MyHC isoforms expressed in specific muscles. Muscles of the head and neck such as the masseter muscle show a more diverse expression of MyHC isoforms than limb muscles [52] and filaments. c Illustration of the MyHC dimer with approximate binding sites for ATP, actin, myosin-binding protein C, myomesin-1, M-protein and titin. The assembly competence domain in the distal rod region is indicated. The different regions of the MyHC (S1, S2 and light meromyosin, LMM) are indicated by different colors

Table 1 Myosin heavy chain isoforms expressed in human muscle

\begin{tabular}{|c|c|c|}
\hline Protein & Gene & Muscle fiber type \\
\hline $\mathrm{MyHC} \mathrm{IIx/d}$ & MYH1 & Type $2 \mathrm{~B}$ \\
\hline МyHC IIa & MYH2 & $\begin{array}{l}\text { Type } 2 \mathrm{~A} \\
\text { Extraocular muscle }\end{array}$ \\
\hline Embryonic MyHC & МYH3 & $\begin{array}{l}\text { Fetal development } \\
\text { Muscle regeneration }\end{array}$ \\
\hline$\alpha$-cardiac MyHC & MYH6 & Heart atria \\
\hline MyHC I & MYH7 & Type 1 \\
\hline$\beta$-Cardiac MyHC & & Heart ventricles \\
\hline Fetal MyHC & МYH & $\begin{array}{l}\text { Fetal development } \\
\text { Muscle regeneration }\end{array}$ \\
\hline Smooth muscle MyHC & МYH11 & Smooth muscle \\
\hline Extraocular MyHC & MYH13 & Extraocular muscle \\
\hline
\end{tabular}

very fast contracting fibers found in extraocular muscles express extraocular MyHC isoform (MYH13) [54].

The non-muscle conventional class II MyHC genes MYH9 and MYH10 encode the non-muscle myosins IIA (MYHIIA) and IIB (MYHIIB), whereas MYH11 encodes smooth muscle MyHC.

\section{Myosin heavy chain diseases}

The first striated muscle $\mathrm{MyHC}$ isoform associated with disease in humans was slow/ $\beta$ cardiac MyHC (MYH7) [25]. 
More than 200 different dominant mutations in MYH7 have been associated with hypertrophic and dilated cardiomyopathy. Mutations in slow/ $\alpha$-cardiac MyHC (MYH6) have been reported to cause hypertrophic and dilated cardiomyopathy and atrial septal defect $[14,16]$.

MYH9-related disorders are autosomal dominant syndromes, variably affecting platelet formation, hearing, and kidney function, and result from mutations in the human nonmuscle myosin IIA heavy chain gene (MYH9). They have previously been described as distinct disorders including Sebastian, Fechtner and Epstein syndromes and May-Hegglin anomaly [7, 27].

The first pure skeletal myopathy associated with an identified MyHC mutation was a MyHC IIa myopathy, associated with a dominant $M Y H 2$ mutation that was described in 2000 [40]. Since then, mutations in genes encoding different MyHC isoforms (MYH2, MYH3, MYH7 and $M Y H 8$ ) have been associated with various skeletal muscle diseases, which are summarized in Table 2.

Loss of thick filaments and myosin, but preserved thin filaments can be seen as an unspecific alteration in various conditions such as dermatomyositis but more typically in critical illness myopathy [37]. This loss of myosin and other proteins associated with the thick filaments is frequently triggered by systemic corticosteroid hormone treatment, postsynaptic block of neuromuscular transmission and prolonged mechanical ventilation. The loss of myosin can be identified by electron microscopy showing a characteristic disappearance of thick filaments or by measuring the ratio of myosin to actin after separation of muscle proteins by gel electrophoresis.

\section{Myopathies associated with developmental MyHC isoforms, $\mathrm{MYH3}$ and $\mathrm{MYH8}$}

The essential roles of embryonic and fetal MyHC isoforms for normal fetal development has been highlighted by the identification of dominant $M Y H 3$ and $M Y H 8$ mutations associated with distal arthrogryposis (DA) syndromes. In addition to common DA manifestations such as clubfeet and clenched fists these syndromes frequently include also decreased movement of proximal joints, facial dysmorphism and other manifestations [8, 26].

At least 18 mutations in the globular head and rod domains of $M Y H 3$ have been associated with DA1, DA2A (Freeman-Sheldon syndrome) and DA2B (Sheldon-Hall syndrome) [3, 71, 79]. The amino acid at position 672 (R672) is the most frequently mutated residue associated with Freeman-Sheldon syndrome indicating a mutational hotspot of this residue [79]. One mutation has been identified in $M Y H 8$ in several unrelated families with the trismuspseudocamptodactyly syndrome $[78,82]$. Interestingly, this mutation in $M Y H 8$ affects the residue R764 (R764Q), which is paralogous to R672 in MYH3. The embryonic and fetal MyHCs are expressed during embryonic and fetal development $[24,31]$ and it has been suggested that mutations in MYH3 and MYH8 cause a developmental myopathy resulting in reduced fetal movement and joint contractures $[71,79]$. There are few reports on muscle pathology in distal arthrogryposis associated with MyHC mutations. These reports are limited to muscle biopsies from children and adults, which show minor unspecific changes [71].

\section{Myopathies associated with MyHC IIa, MYH2}

Dominant as well as recessive mutations in $M Y H 2$ that cause myopathy have been identified.

Autosomal dominant MyHC IIa myopathy, which has also been referred to as "autosomal dominant myopathy with congenital joint contractures, ophthalmoplegia and rimmed vacuoles", was originally identified as a muscle disorder in western Sweden [19]. The disease was mapped to chromosome 17p13.1 [39] and later demonstrated to be caused by a heterozygous missense mutation in $\mathrm{MYH} 2$ encoding MyHC IIa [40]. The mutation changes the highly conserved and negatively charged glutamate at position 706 to the positively charged lysine (E706K). The mutated residue is located in the SH1 helix in the core of motor domain, which is highly conserved through evolution.

A prenatal onset of the disease was indicated by multiple joint contractures that were present at birth in the majority of the patients. The joint contractures preferentially involved the fingers and/or hips and generally resolved early in childhood. Hypotonia was not a prominent feature and the early development was normal. External ophthalmoplegia was present in all patients, ranging from a slight impairment of upward gaze in affected children to a generalized ophthalmoparesis in some adult cases. The muscle weakness and atrophy predominantly involved proximal muscles of the shoulder and pelvic girdles, and also back and hand muscles. Atrophy of the quadriceps muscles was prominent in the more severely affected adults. The muscle weakness was remarkably variable. Most children and adolescents and some adults were mildly affected, whereas some adults had experienced progressive muscle weakness affecting ambulation from age 30 to 50 years. While mildly affected cases had normal serum creatine kinase (s-CK) levels, it was slightly elevated in the family members showing a progressive course. A fine action hand tremor has been noticed in several cases.

Muscle pathology was highly variable, also in different muscles of the same individual. A consistent finding was a 
Table 2 Myopathies associated with mutations in skeletal muscle myosin heavy chains

\begin{tabular}{|c|c|c|c|}
\hline $\begin{array}{l}\text { Gene } \\
\text { Protein }\end{array}$ & Disease & Major clinical characteristics & Skeletal muscle pathology \\
\hline \multirow[t]{2}{*}{$\begin{array}{l}\text { MYH2 } \\
\text { МyHC IIa }\end{array}$} & $\begin{array}{l}\text { Autosomal dominant myopathy } \\
\text { with congenital joint } \\
\text { contractures, ophthalmoplegia } \\
\text { and rimmed vacuoles } \\
\text { OMIM \#605637 }\end{array}$ & $\begin{array}{l}\text { Congenital, reversible joint contractures. } \\
\text { Ophthalmoplegia. } \\
\text { Mild proximal muscle weakness in childhood. } \\
\text { Progressive course in some adults affecting } \\
\text { ambulation }\end{array}$ & $\begin{array}{l}\text { Rimmed vacuoles with protein aggregates, } \\
\text { composed of } 15-20 \mathrm{~nm} \text { tubulofilaments, in } \\
\text { adults with progressive course and } \\
\text { dystrophic muscle changes. Structural } \\
\text { alterations with minicores in type } 2 \text { fibers in } \\
\text { childhood and in mildly affected muscles of } \\
\text { adults. Reduced number and small type } 2 \\
\text { fibers in some cases. }\end{array}$ \\
\hline & $\begin{array}{l}\text { Autosomal recessive myopathy } \\
\text { with ophthalmoplegia }\end{array}$ & $\begin{array}{l}\text { Mild to moderate muscle weakness, usually } \\
\text { mild facial involvement. Ophthalmoplegia }\end{array}$ & $\begin{array}{l}\text { Complete absence of type } 2 \mathrm{~A} \text { muscle fibers. } \\
\text { Variable, unspecific myopathic changes } \\
\text { with fatty infiltration. Type } 2 \mathrm{~B} \text { fibers may } \\
\text { be lacking. }\end{array}$ \\
\hline $\begin{array}{l}\text { MYH3 } \\
\text { Embryonic } \\
\quad \text { MyHC }\end{array}$ & $\begin{array}{l}\text { DA1 OMIM \#108120 } \\
\text { Freeman-Sheldon syndrome, } \\
\text { DA2A, } \\
\text { OMIM \#193700 } \\
\text { Sheldon-Hall syndrome, } \\
\text { DA2B, OMIM \#601680 }\end{array}$ & $\begin{array}{l}\text { Multiple congenital joint contractures with } \\
\text { predominant distal involvement. No muscle } \\
\text { weakness }\end{array}$ & Minor unspecific changes \\
\hline \multirow{4}{*}{$\begin{array}{l}\text { MYH7 } \\
\text { MyHC I } \\
(\text { (-cardiac } \\
\text { MyHC) }\end{array}$} & $\begin{array}{l}\text { Familial hypertrophic/dilated } \\
\text { cardiomyopathy, } \\
\text { OMIM \#192600 }\end{array}$ & $\begin{array}{l}\text { Cardiac failure, arrhythmia, } \\
\text { sudden cardiac arrest }\end{array}$ & $\begin{array}{l}\text { Irregular structure with cores in type } 1 \text { muscle } \\
\text { fibers in some patients }\end{array}$ \\
\hline & $\begin{array}{l}\text { Myosin storage myopathy } \\
\text { OMIM \#608358 }\end{array}$ & $\begin{array}{l}\text { Onset from childhood to middle age. } \\
\text { Weakness of limb girdle, scapuloperoneal } \\
\text { or distal muscles. Mild weakness or severe } \\
\text { weakness affecting ambulation }\end{array}$ & $\begin{array}{l}\text { Subsarcolemmal protein aggregates in type } 1 \\
\text { fibers that reacts with antibodies to myosin } \\
\text { but not to desmin. Granular and partly } \\
\text { filamentous structure on EM. Myofibrillar } \\
\text { disarray. }\end{array}$ \\
\hline & $\begin{array}{l}\text { Laing early-onset distal myopathy, } \\
\text { OMIM \#160500 }\end{array}$ & $\begin{array}{l}\text { Usually onset of distal muscle weakness in } \\
\text { childhood, but may be much later. Slowly } \\
\text { progressive course with initial weakness of } \\
\text { ankle dorsiflexion and "hanging big toe" } \\
\text { sign }\end{array}$ & $\begin{array}{l}\text { Fiber size variability, internalized nuclei, } \\
\text { frequently small type } 1 \text { fibers. Dystrophic } \\
\text { changes may occur. Rimmed vacuoles and } \\
\text { protein aggregates in rare cases, either as } \\
\text { inclusions of } 15-20 \mathrm{~nm} \text { tubulo-filaments or } \\
\text { as cytoplasmic bodies. Minicores may be } \\
\text { frequent. }\end{array}$ \\
\hline & $\begin{array}{l}\text { Scapuloperoneal and limb girdle } \\
\text { syndromes }\end{array}$ & $\begin{array}{l}\text { Scapuloperoneal or limb girdle muscle } \\
\text { weakness without morphological features of } \\
\text { myosin storage }\end{array}$ & $\begin{array}{l}\text { Unspecific changes including fiber type } \\
\text { disproportion }\end{array}$ \\
\hline $\begin{array}{l}\text { МYH8 } \\
\text { Fetal } \\
\text { MyHC }\end{array}$ & $\begin{array}{l}\text { Trismus and pseudocamtodactyly } \\
\text { syndrome, DA7 } \\
\text { OMIM\#158300 }\end{array}$ & $\begin{array}{l}\text { Congenital contractures of hands, feet and } \\
\text { jaws with trismus and hand and foot } \\
\text { deformities with pseudocamptodactyly }\end{array}$ & Not described \\
\hline
\end{tabular}

EM Electron microscopy

predominant involvement of type 2A muscle fibers (Fig. 2). In children and mildly affected adults the type $2 \mathrm{~A}$ fibers were reduced in number, frequently smaller than normal and often demonstrating disorganization of myofibrils, similar to what is observed in multi-mini core disease [19]. Adults with progressive course and increased s-CK levels demonstrated dystrophic muscle pathology with increased interstitial fat and connective tissue. The presence of rimmed vacuoles in many fibers (Fig. 3) in the more advanced cases was the reason at that time to consider this myopathy as a variant of hereditary inclusion body myopathy (hIBM3). The number of rimmed vacuoles was variable also in the severely affected cases. These rimmed vacuoles are associated with inclusions that stain positively for ubiquitin and sequestosome 1 (SQSM1/p62) (Fig. 4a, b). SQSM1/p62 is a component of many disease-associated intracellular multiprotein aggregates and a useful marker for the identification of inclusions in sporadic inclusion body myositis [18, 47]. A few inclusions show congophilia (Fig. 4c). Inclusions of tubulofilaments measuring $15-21 \mathrm{~nm}$ in diameter are present, usually in 
association with rimmed vacuoles (Figs. 5, 6). Intranuclear filaments can also be observed (Fig. 7).

The severity of the disease was apparently related to the amount of expressed MyHC IIa protein in muscle [75]. Severely affected individuals and muscles showed a large proportion of type $2 \mathrm{~A}$ muscle fibers, and the fibers with rimmed vacuoles expressed MyHC IIa. Studies on the effects of endurance training have been performed $[69,74]$. An 8-week endurance training program on a stationary exercise bicycle had no adverse effects. The peak watt and walking speed increased, but there was no significant increase in muscle strength or isometric endurance [69]. The training program resulted in a shift in expression from fast to slow MyHC isoforms. There was no significant change in the MyHC IIa expression, but frequent hybrid fibers expressing more than one $\mathrm{MyHC}$ isoform were identified [74].

Patients with recessive MyHC IIa mutations have recently been identified. The so far published cases are homozygous or compound heterozygous for truncating mutations in $M Y H 2$, accompanied by complete loss of MyHC IIa protein and absence of type 2A muscle fibers [70]. The clinical picture was surprisingly mild with minor or moderate generalized muscle weakness including facial muscle weakness. A consistent finding was external ophthalmoplegia, which was only occasionally associated with ptosis. Magnetic resonance imaging (MRI) of lower limb muscles in two cases demonstrated selective involvement of certain muscles with fatty infiltration. There was predominant involvement of medial gastrocnemius in the lower legs, combined with predominant involvement of the semitendinosus, gracilis and vastus lateralis muscles in the thigh.

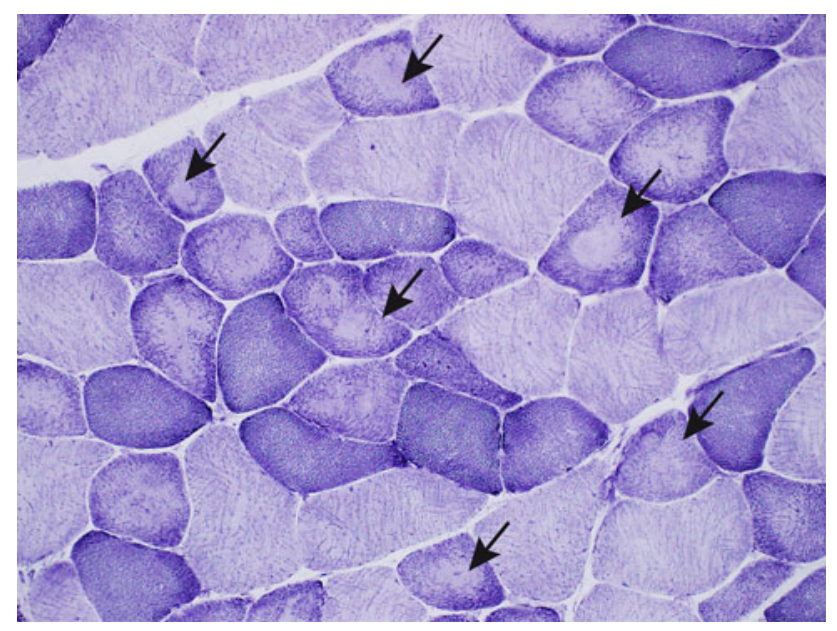

Fig. 2 Dominant myosin IIa myopathy. Biopsy of the deltoid muscle of a 38-year-old man showing alterations of the type 2A fibers (arrows). NADH-tetrazolium reductase
Muscle biopsy demonstrated in addition to complete loss of MyHC IIa protein, unspecific myopathic changes with fiber size variability, internalized nuclei and interstitial fatty infiltration [70]. Some muscle biopsy samples demonstrated type 1 fiber uniformity. Unlike the dominant MyHC IIa myopathy, no rimmed vacuoles or protein aggregates have been identified.

\section{Myopathies associated with slow/beta MyHC, MYH7}

Overall, mutations in $M Y H 7$ are predominantly missense mutations located in the globular myosin head, potentially affecting the binding sites for actin or nucleotides but there are also numerous mutations in the rod region. More than 200 different mutations have been associated with either hypertrophic or dilated cardiomyopathy, but there are also pure skeletal myopathies and combination of myopathy and cardiomyopathy.

\section{Myosin storage myopathy}

Myosin storage myopathy is a protein aggregate myopathy associated with myosin accumulation [76]. Mutations that cause myosin storage myopathy are located in the distal end of the tail of slow/ $\beta$ cardiac MyHC, corresponding to exons $37-40$ of $M Y H 7$ (Fig. 8).

A dominant missense mutation changing the highly conserved and positively charged arginine at position 1845 to the uncharged, aromatic tryptophan (R1845W) was the first mutation identified in myosin storage myopathy. This mutation has been reported in several unrelated cases indicating that the $\mathrm{C}$ nucleotide at position 5533 is a mutational hotspot $[32,34,55,65,76]$. Two additional dominant missense mutations, H1901L [10] and L1793P [22], have later been reported to cause myosin storage myopathy. Recently, a heterozygous A to $\mathrm{G}$ transition in exon 40 of $M Y H 7$ was reported in several individuals of a five-generation family [51]. The mutation is predicted to change the terminal stop codon (TAG) to a tryptophan (W), resulting in an elongation of the C-terminal tail region (X1936WfsX32). Another dominant in frame deletion of the amino acid lysine at position 1784 (K1784del) in exon 37 of $M Y H 7$ has recently been reported in a case with myosin storage myopathy [68]. Myosin storage myopathy combined with cardiomyopathy was reported in three siblings homozygous for a missense mutation (E1883K), but with apparently unaffected parents [72]. Mutations in the distal rod region of slow $/ \beta$ cardiac MyHC associated with myosin storage myopathy may thus be either dominant or recessive.

Myosin storage myopathy was first reported as a familial myopathy with probable lysis of myofibrils in type 1 fibers by Cancilla et al. [13]. The inclusions were described as 

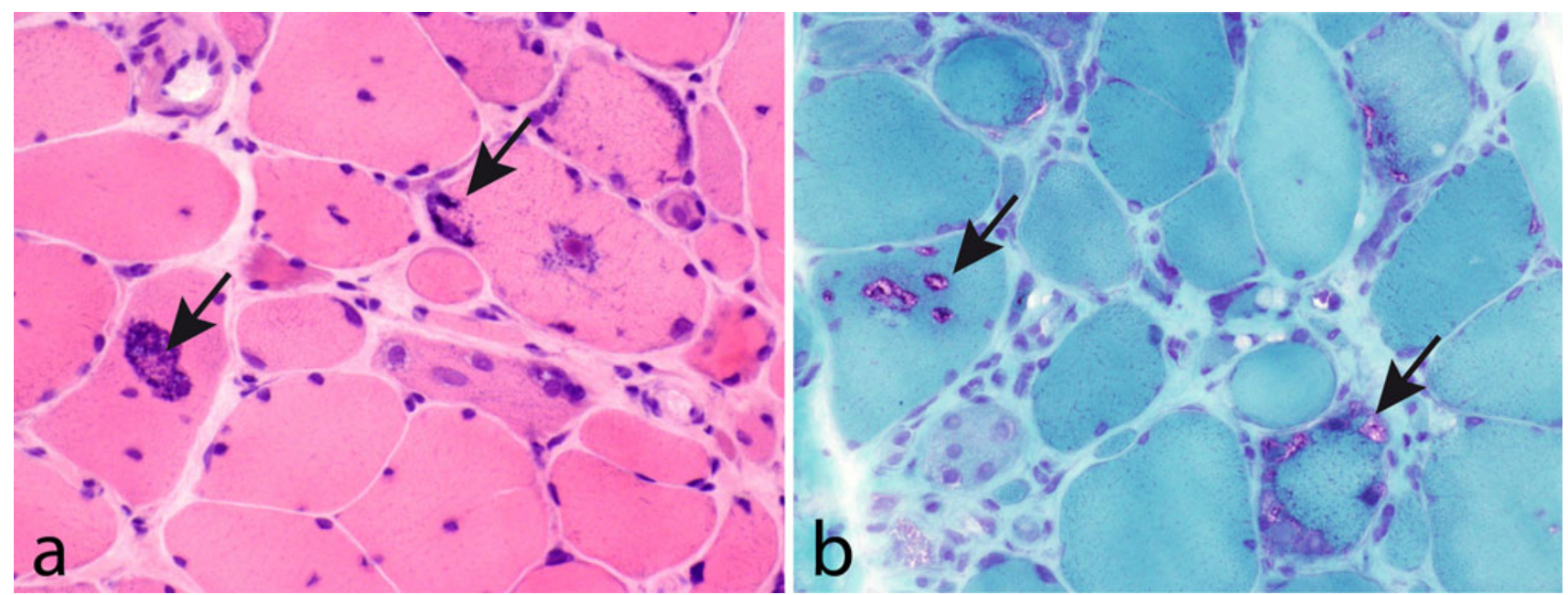

Fig. 3 Dominant myosin IIa myopathy. Biopsy of the quadriceps muscle of a 38-year-old man demonstrating variability of fiber size, increased interstitial connective tissue, and frequent fibers with rimmed vacuoles. a Hematoxylin and eosin; b Gomori trichrome
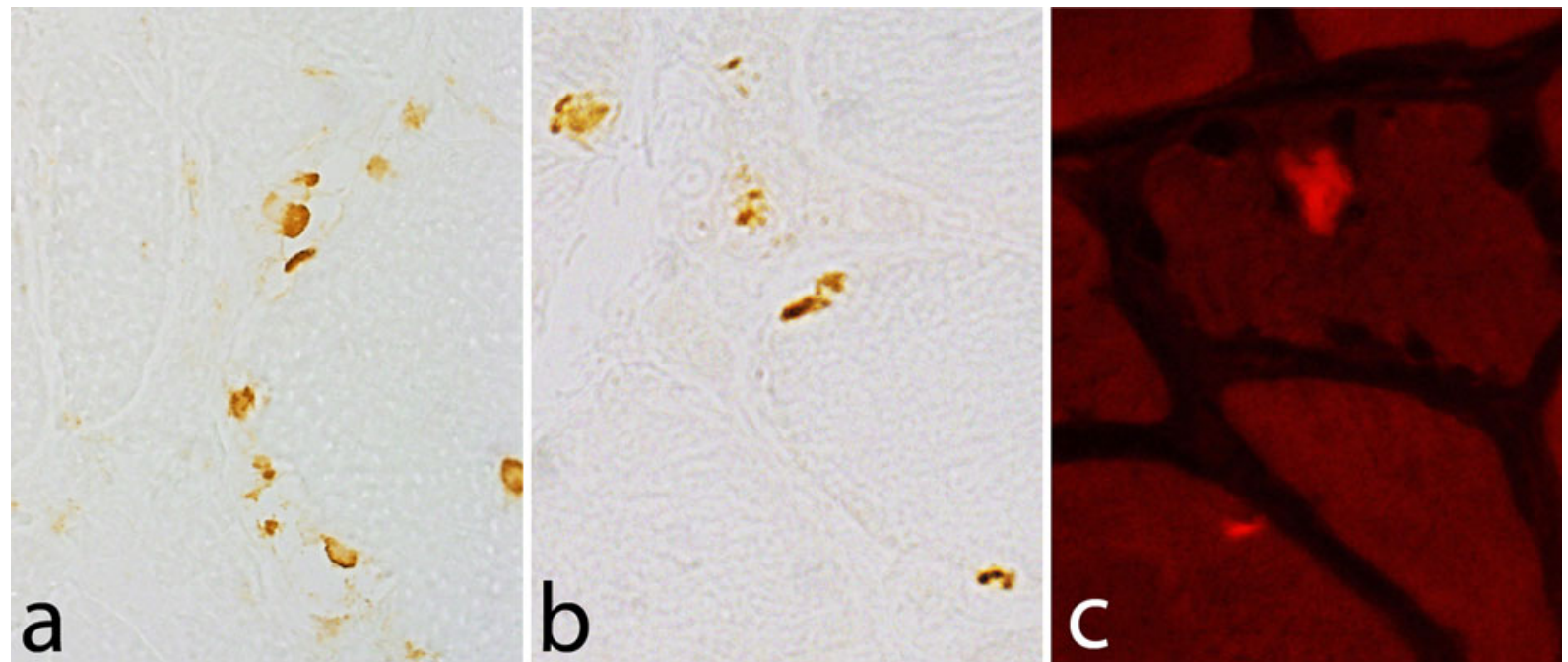

Fig. 4 Dominant myosin IIa myopathy. Several muscle fibers show inclusions that are immunoreactive to antibodies against p62 (a) and ubiquitin (b). Amyloid is present in a few inclusions as revealed by Congo staining and fluorescence microscopy with Texas red filter (c)

hyaline bodies because of their unstructured appearance at light microscopy [15], and the term hyaline body myopathy was used in some subsequent case reports. After the discovery that the storage material consists of mainly myosin heavy chain immunoreactive material and that the mutated gene is the slow $/ \beta$ cardiac MyHC gene, MYH7, the term myosin storage myopathy was introduced [76] and has been adopted and used in most subsequent reports.

The clinical manifestations are highly variable ranging from no weakness to severe impairment of ambulation $[9,11,13,15,34,42,55,59,65,68,76,81]$. This variability can also be present within a family [11, 55, 81]. Onset is usually in childhood but may be much later. Presenting signs and symptoms are often delayed motor milestones, difficulties in climbing stairs or running and a waddling gate. The distribution of muscle weakness is usually proximal in upper extremities with difficulties in lifting the arms above the shoulder level and scapular winging has been described in many cases. In the lower extremities a distal involvement with foot drop is common and pseudo-hypertrophy of the calves is frequently encountered. Apart from a scapulo-peroneal distribution of weakness, a predominant limb-girdle weakness can be seen in some cases $[13,15]$. The course is usually slowly progressive and scoliosis sometimes supervenes [11, 68] and some patients need assisted ventilation.

Evidence of cardiomyopathy associated with the myopathy is usually not found. However, in one woman with muscle weakness since age 30, hypertrophic cardiomyopathy was diagnosed at age 51 [81]. Her 24-year-old 


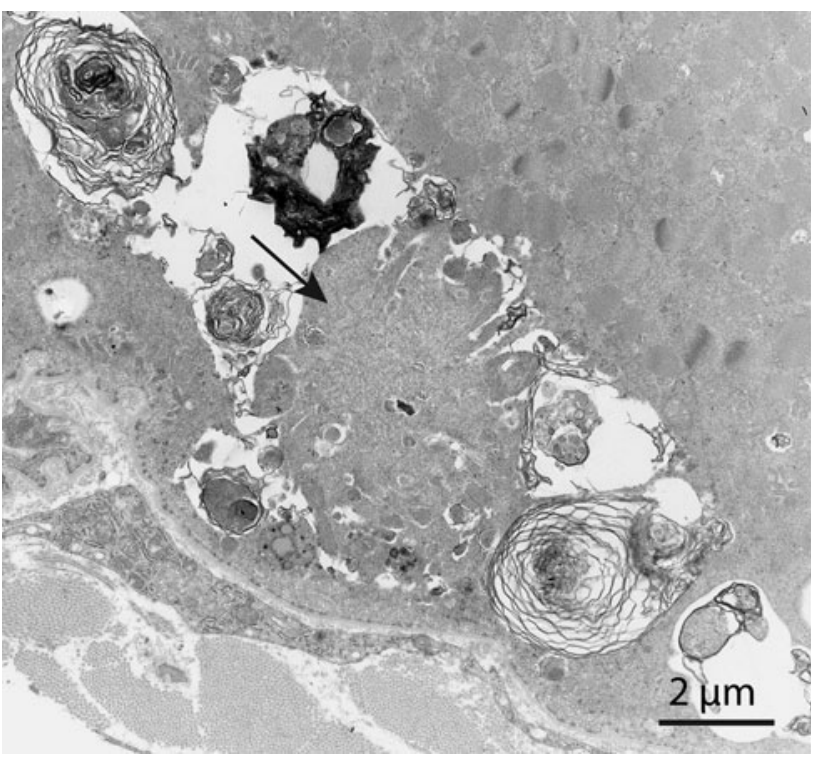

Fig. 5 Dominant myosin IIa myopathy. Electron microscopy reveals a filamentous inclusion (arrow) associated with a rimmed vacuole with degradation products

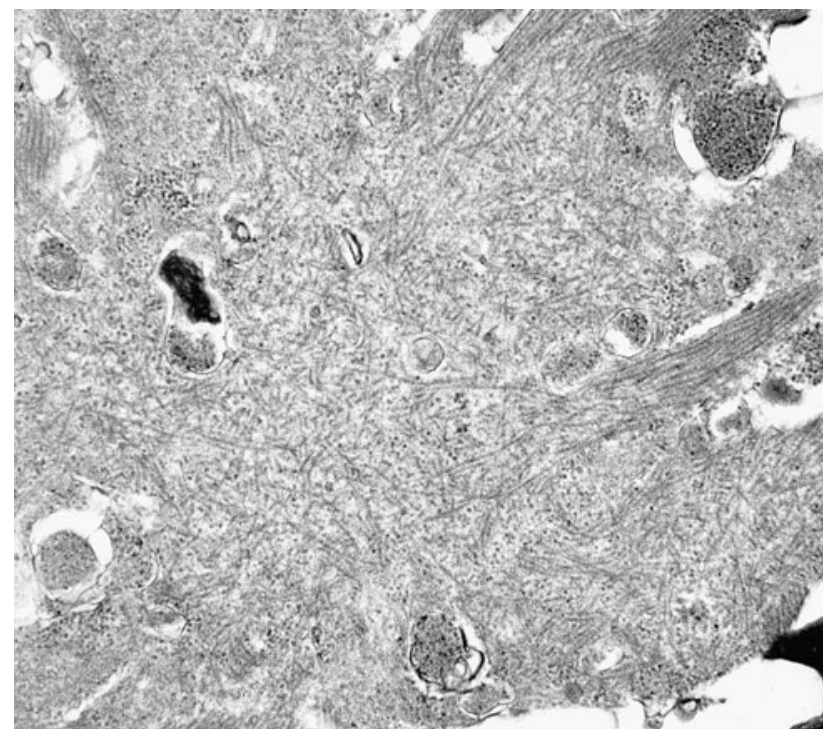

Fig. 6 Dominant myosin IIa myopathy. Electron microscopy demonstrating an inclusion composed of 15-20 nm tubulofilaments

daughter presented with cardiac failure already at age 3 months and was diagnosed with signs of left ventricular non-compaction. Three severely affected siblings homozygous for apparently recessive mutations had myosin storage myopathy and hypertrophic cardiomyopathy with cardiac failure that was lethal in two cases [72].

Magnetic resonance imaging (MRI) of muscle in myosin storage myopathy in ten individuals from one family demonstrated in the lower limbs early involvement of the biceps femoris and semimembranosus muscles and relative sparing of the semitendinosus in the posterior compartment of the

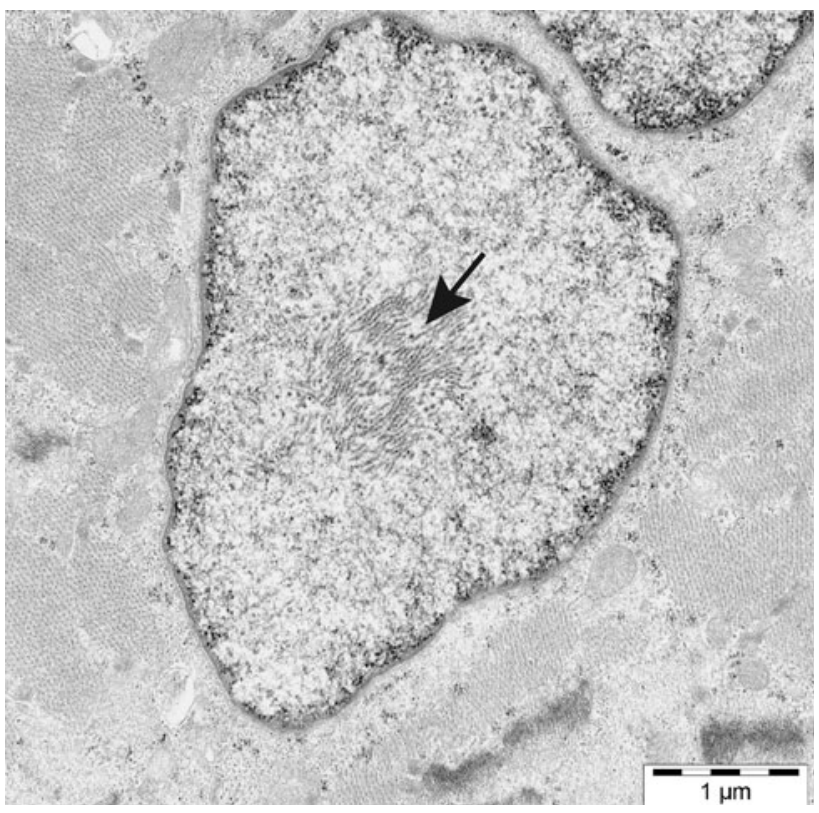

Fig. 7 Electron micrograph illustrating intranuclear filaments (arrow) in dominant myosin IIa myopathy

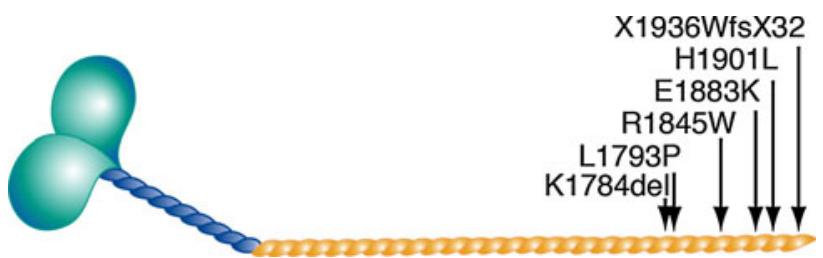

Fig. 8 Mutation in $M Y H 7$ associated with myosin storage myopathy. They are all located in the distal rod region of the MyHC

thigh [55]. In the distal muscles of the legs there was a predominant involvement of the medial gastrocnemius, tibialis anterior, extensor hallucis longus and extensor digitorum longus muscles. In the upper limbs there was a predominant involvement of the deltoid muscle. There was no asymmetry.

Muscle biopsy demonstrates the characteristic subsarcolemmal accumulation of material that is slightly eosinophilic and stains light green in trichrome but there is no NADHtetrazolium-reductase staining (Fig. 9). By light microscopy the material looks completely unstructured giving it a hyaline appearance (Fig. 10a). There is no immunoreactivity of dystrophin, sarcoglycans or merosin in relation to the stored material, but immunostaining of desmin and also of $\alpha \beta$-crystalline may show a rim of intense staining around the stored material (Fig. 10b) [11, 55]. The stored material is restricted to type 1 fibers and usually demonstrates myofibrillar ATPase activity and immunoreactivity to slow $/ \beta$ cardiac MyHC (Fig. 10c) [11, 51, 55, 68, 76, 81]. However, there are also reports indicating that the accumulated material may be immunoreactive to antibodies against fast myosin isoforms $[15,65]$. We have found the stored material to be 
immunoreactive with antibodies against ubiquitin (Fig. 10d), which is different from a previous report [11], but we have not identified any p62 positive material. The stored material shows no cytochrome $c$ oxidase or succinate dehydrogenase activity (Fig. 11a), but there is usually a rim of increased enzyme activity in the periphery corresponding to mitochondria (Fig. 11b). The inclusion bodies are not limited by a membrane but the stored material can be seen between partly disintegrated myofibrils in the vicinity of the main storage body (Figs. 11b, 12a). At higher magnification the storage material has a granular appearance and a few abortive filaments can be seen (Fig. 12b). The inclusions in myosin storage myopathy differ from those in cap disease as the latter contain remnants of sarcomeres with thickened and fragmented Z-lines and thin filaments. The caps show positive immunostaining to desmin whereas the inclusions in myosin storage myopathy are unstained.

\section{Laing (Gowers-Laing) distal myopathy}

Most patients reported with Laing distal myopathy have dominant mutations in $M Y H 7$ located in exon 32-36 in the mid region of the MyHC rod including: R1500P, E1508del, L1591P, A1603P, K1617del, A1663P, L1706P and K1729del (Fig. 13) [21, 43, 44, 80]. The L1729del mutation has been identified in multiple unrelated patients [44, 45]. However, MYH7-associated distal myopathy is not restricted to mutations in this region. Three mutations have been identified in the globular head (T441M, V606M and R783P) [20, 29, 53], and three mutations have been identified in the distal rod region overlapping with the myosin storage myopathy region (E1801K, E1856K and K1784del) (Fig. 13) [77, 80]. Five of these six mutations were associated with distal myopathy and cardiomyopathy. Muscle morphology was not reported in the patients with the three distal mutations (K1784del, E1801K and E1856K) [77, 80] and it cannot be excluded that they were cases of myosin storage myopathy, since the K1784del mutation has been associated with myosin storage myopathy [68]. For classification of diseases, which are associated with mutations in the LMM of slow/ $\beta$ cardiac MyHC and may show clinical overlap, it is essential to perform muscle biopsy.

Laing distal myopathy was first linked to chromosome $14 \mathrm{q} 11$ [35, 83], and it was later demonstrated to be caused by mutations in MYH7 [43]. Most cases have presented early in childhood and hence the term "early-onset" distal myopathy has been used in several reports. Onset is, however, not always in childhood but can occur with a range from congenital to 50 years [35, 36, 41, 44, 77, 83]. The clinical course in typical cases starts with early-onset weakness of ankle dorsiflexors and a "hanging big toe" sign. Calf hypertrophy may be present. During the slowly progressive course finger extensor and neck flexion weakness and later also proximal limb and facial muscle weakness supervenes. Patients usually remain ambulant. Serum CK levels are normal or moderately elevated. Cardiac involvement is usually not a feature of Laing distal myopathy but there are a few exceptions with diseases associated with $M Y H 7$ mutations and presenting with distal myopathy as well as cardiomyopathy $[20,29,53,80]$.

Muscle MRI has demonstrated early changes in the anterior compartments of the lower leg especially the extensor hallucis longus and tibialis anterior muscles [21, $44,77]$. Later in the course and in more severely affected patients additional muscles in the thigh may be involved.

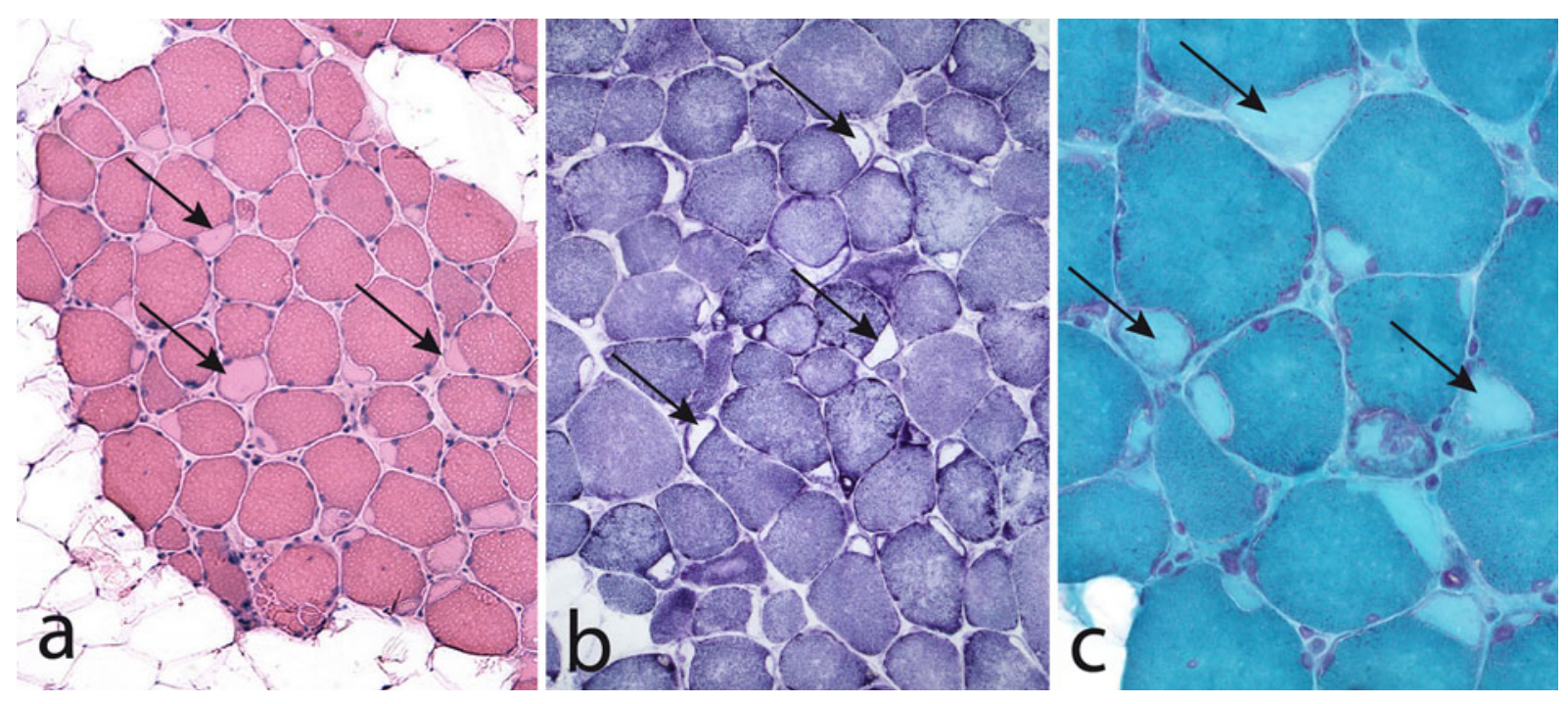

Fig. 9 Myosin storage myopathy. There is fatty infiltration and numerous muscle fibers with subsarcolemmal accumulation of material (arrows) that stains faintly red by hematoxylin-eosin (a) is unstained by NADH-tetrazolium reductase (b) and stains light green in Gomori trichrome (c) 

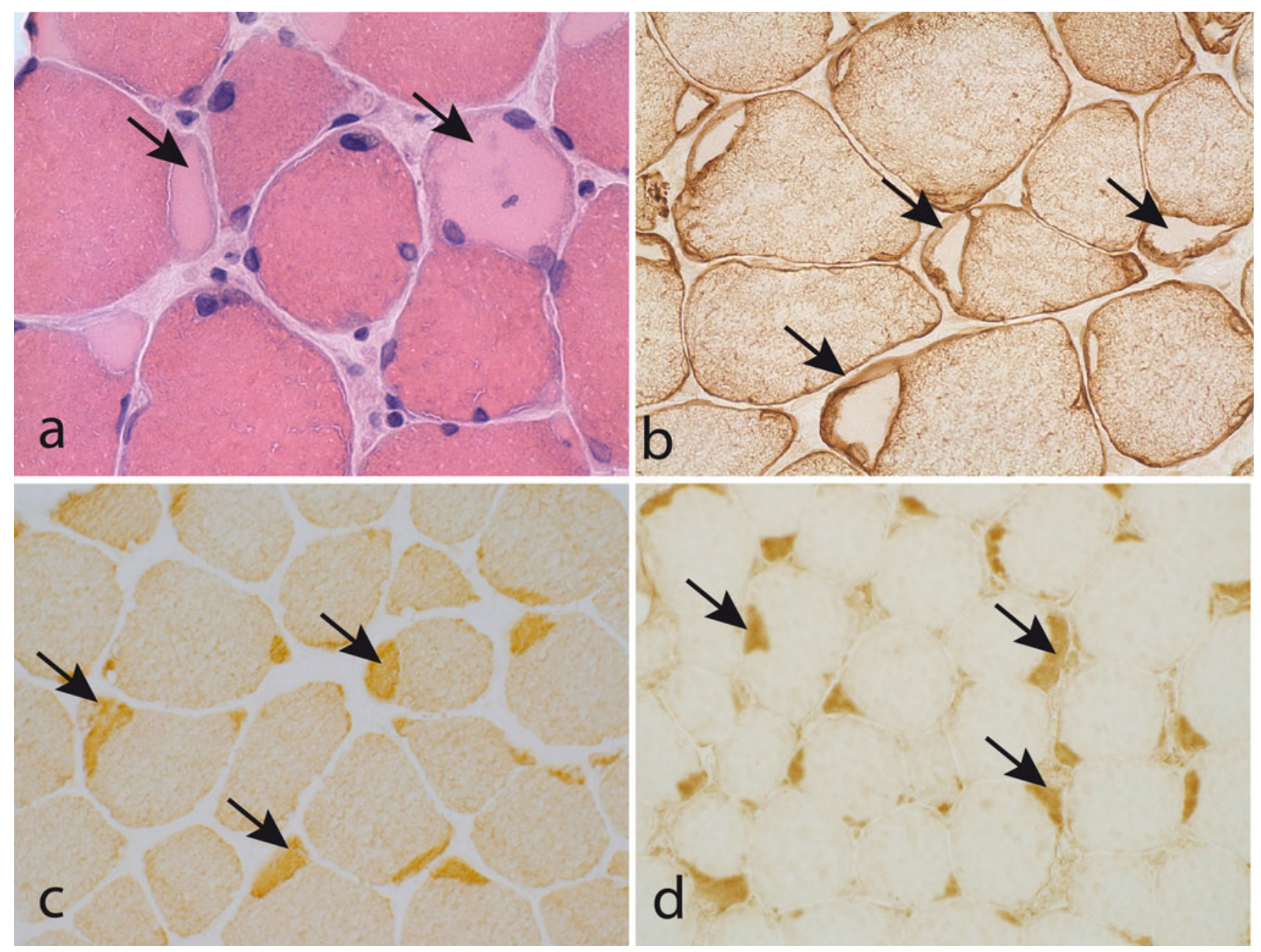

Fig. 10 Myosin storage myopathy. The inclusions (arrows) appear unstructured in hematoxylin-eosin (a) and are surrounded by a rim of desmin (b). The inclusions are immunoreactive with antibodies against slow/ $\beta$ cardiac $\mathrm{MyHC}$ (c) and ubiquitin (d)

Muscle pathology has been reported in most case reports and more systematically in patients from a few families [36, 44, 83]. The pathological changes are, unlike those in myosin storage disease, variable and unspecific. Common findings are predominance of type 1 fibers and numerous small type 1 fibers (Fig. 14), which may appear as fiber type disproportion. Internal nuclei are usually present and structural abnormalities, especially minicores, in addition to mitochondrial abnormalities are common. Muscle fiber necrosis can be seen but is usually not conspicuous. The muscle may show severe atrophy with fat and connective tissue replacement. Protein aggregates are usually not seen, but rimmed vacuoles and filamentous inclusions of the same type as in MyHC IIa myopathy and inclusion body myositis have been observed [41, 77]. In one case cytoplasmic bodies and myofibrillar alterations similar to those seen in myofibrillar myopathies were reported [77].
Other skeletal muscle phenotypes associated with $M Y H 7$ mutations

Although the most important skeletal muscle manifestations of $\mathrm{MYH7}$ mutations are referred to as either myosin storage myopathy or Laing distal myopathy several cases cannot be classified into these groups because they either do not display distal muscle weakness or do not exhibit hyaline bodies. Muscle biopsy of some patients with mutations that are known to cause myosin storage myopathy may not reveal the pathognomonic changes, but instead unspecific changes [55] or alterations diagnostic for congenital fiber type disproportion [51]. A few patients with $M Y H 7$ mutations that otherwise cause distal myopathy could be classified as having limbgirdle syndrome or scapuloperoneal myopathy thus overlapping with the clinical features of myosin storage myopathy [44]. In some but not all patients with cardiomyopathy due to MYH7 mutations, but without overt muscle weakness, cores may be identified in skeletal muscle fibers [23]. 


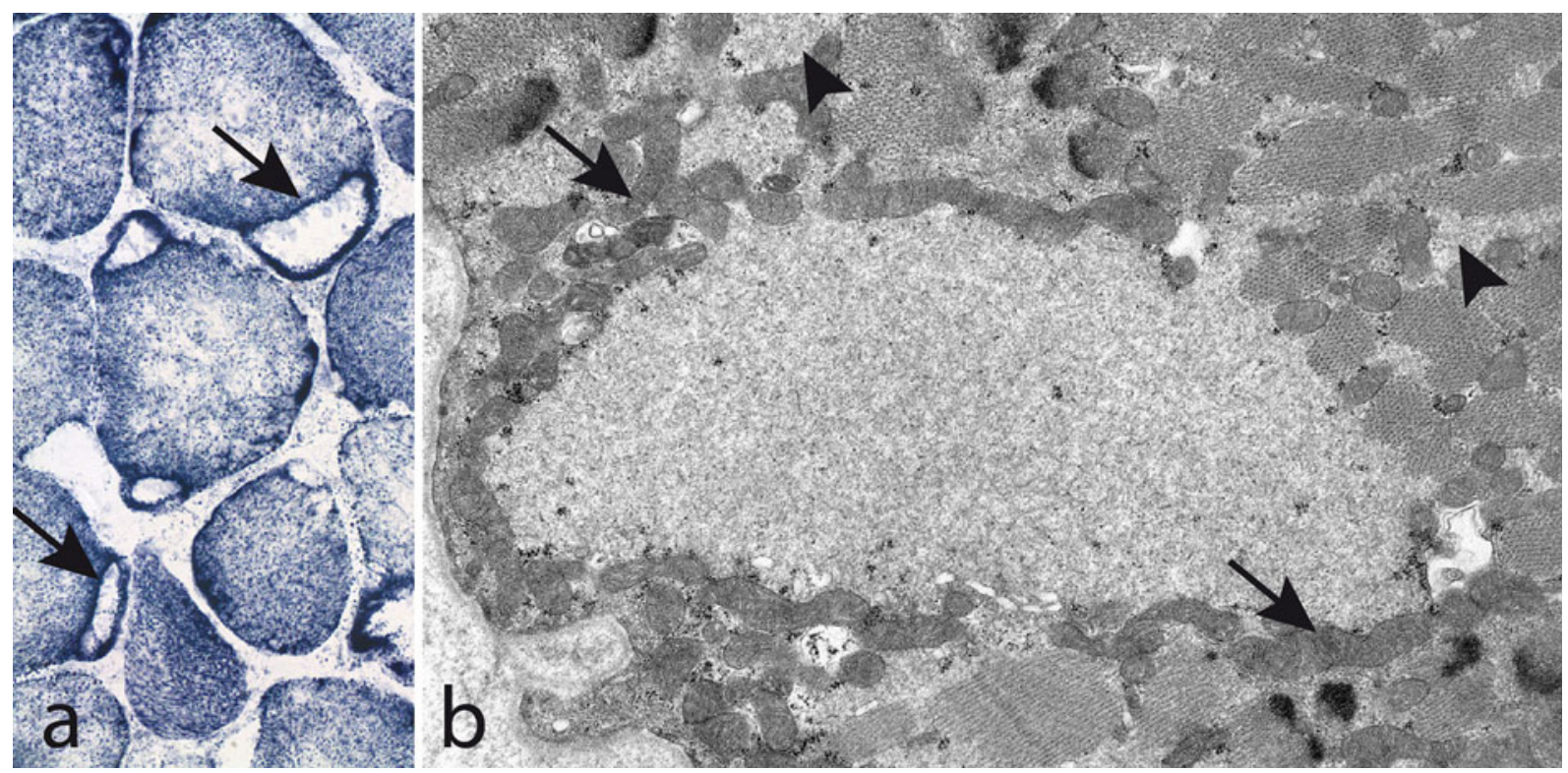

Fig. 11 Myosin storage myopathy. The inclusions are surrounded by a rim of increased succinate dehydrogenase activity (arrows) (a), which corresponds to the presence of numerous mitochondria (arrows) around but not within the inclusions as revealed by electron microscopy (b). There is also storage material between surrounding myofibrils (arrow heads)

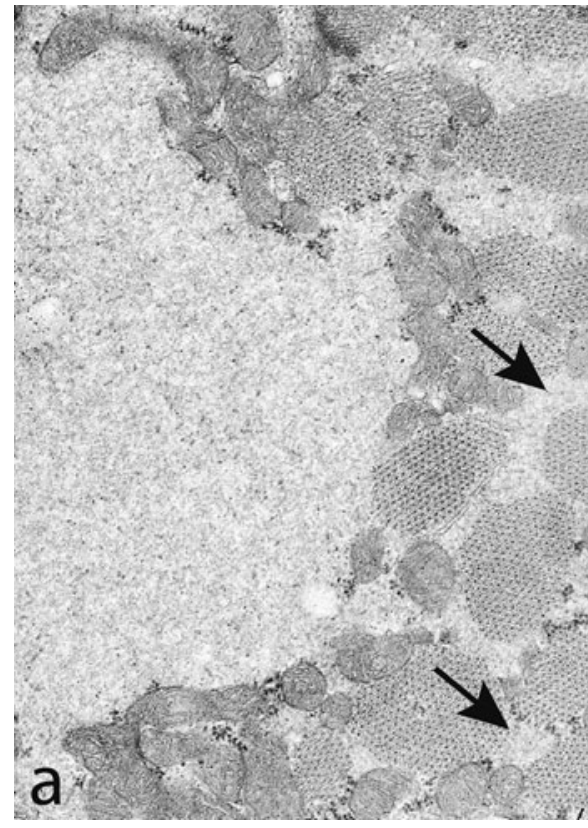

Fig. 12 Myosin storage myopathy. Electron microscopy of storage material. a The inclusions are not limited by any membrane but instead the storage material can be seen surrounding the adjacent

\section{Pathogenesis}

MYH3 mutations and distal arthrogryposis

A correct understanding of the cause of distal arthrogryposis due to $M Y H 3$ mutations would require examination of muscle pathology during the developmental period when MYH3 is expressed. Since MYH3 mutations associated with myofibrils (arrows). b The storage material appears granular and party filamentous and some glycogen particles are also present

distal arthtrogryposis are dominant, it may be hypothesized that they affect muscle function during early development through either haploinsufficiency with insufficient dosage of a functional embryonic MyHC or a dominant negative effect of the mutated allele. Most of the MYH3 mutations are missense, but it is not known whether the mutant allele is expressed. Although the hemizygous loss of MyHC IIa expression is tolerated well in individuals with 


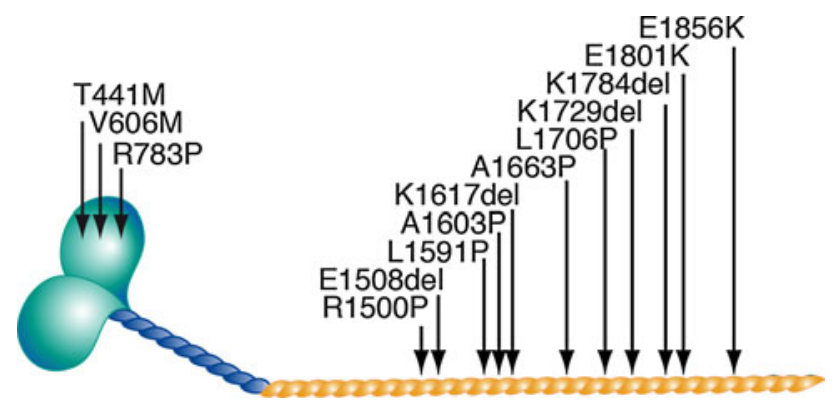

Fig. 13 Mutations in $M Y H 7$ associated with distal myopathy. They are mainly located in mid-rod region of the MyHC, but some are located in the globular myosin head and the distal rod

heterozygous $M Y H 2$ null mutations [70], the situation may be different with embryonic MyHC, since it is a predominant $\mathrm{MyHC}$ isoform expressed during an early period of development. Another possibility would be that $M Y H 3$ mutations impose dominant negative effects by functional or structural alterations as seen in dominant mutations affecting the adult MyHC isoforms. However, studies on disease models are needed to pinpoint the pathogenesis of developmental myopathy caused by $M Y H 3$ mutations.

\section{The MyHC IIa E706K mutation}

The E706K mutation associated with the autosomal dominant MyHC IIa myopathy has been studied at the molecular level in different systems. The mutated residue is situated in the SH1 helix in the core of myosin motor domain, which is strongly conserved throughout the myosin class II family. The SH1 helix plays a central role in the conformational changes of the myosin head during the ATP cycle.
Several studies have suggested impaired functional properties as the primary molecular defect of the E706K mutated MyHC protein. In vitro motility studies on myosin IIa isolated from single muscle fibers of patients carrying the E706K mutation clearly showed a marked reduction of speed [38]. Furthermore, studies on the motor function of E683K mutant myosin of Dictyostelium discoideum, which is equivalent to the human MyHC IIa E706K mutation, demonstrated a threefold reduction of the ATP hydrolysis step followed by the slower acto-myosin dissociation [87]. Consequently, these effects lead to a reduced velocity of contraction. A transgenic C. elegans was generated to simulate MyHC IIa myopathy in order to assess the functional or structural effects of the E706K mutation [73]. Worms that were null mutant for UNC-54 (encoding the major $C$. elegans myosin heavy chain expressed in body wall muscle) were partly rescued by transfection with wild type UNC-54. Transfection with a construct encoding UNC-54 with an $\mathrm{E} 710 \mathrm{~K}$ mutation corresponding to the human MyHC IIa E706K mutation resulted in restored thick filaments but completely paralyzed worms [73]. In addition, mutations in SH1 helix of nonmuscle class II MYHIIA, encoded by MYH9 (R702C and R705H), have been associated with a group of inherited giant-platelet disorders in several families [28]. Association of diseases with mutations in SH1 helix of myosin in both muscle and non-muscle MyHC illustrates the crucial role of this thiol region in the head of myosin for proper function of the protein. These different studies all point to a severe defect of the molecular motor function caused by the E706K mutation.

Structural changes in the muscle fibers and muscle fiber loss are likely to be an additional mechanism causing
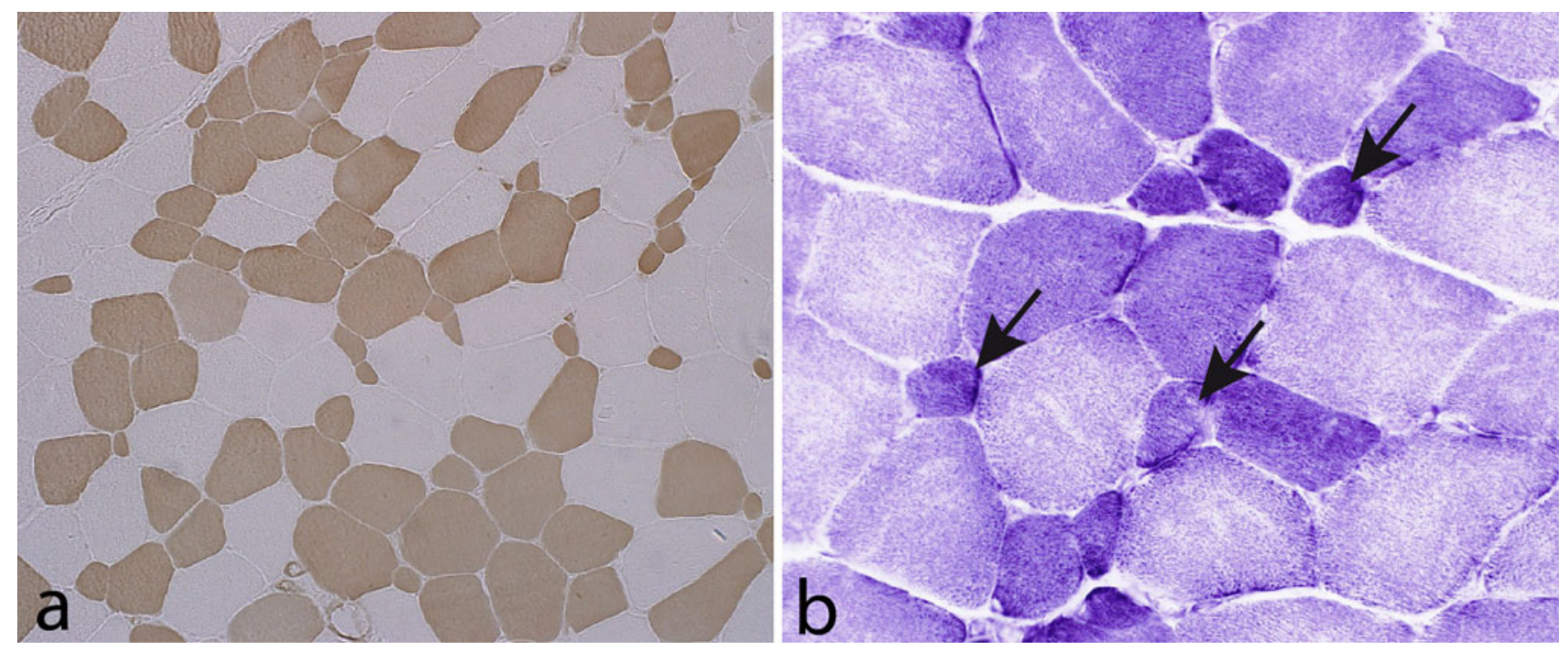

Fig. 14 Tibialis anterior muscle of a 7-year-old boy with MYH7-associated distal myopathy. Many of the type 1 fibers are small (arrows). a Myofibrillar ATPase, $\mathrm{pH} 4.3$ and b NADH-tetrazolium reductase 
muscle weakness. Morphological studies on muscle biopsy specimens have demonstrated a clear correlation between the expression of the mutated MyHC IIa and dystrophic changes in muscle [75]. The high expression of mutant protein combined with aging may cause defective elimination of misfolded proteins, resulting in accumulation of protein aggregates and secondary muscle fiber degeneration. This hypothesis is supported by the accumulation of ubiquitinated and p62-labeled protein aggregates in vacuolated muscle fibers. This mechanism could be similar to what is seen in inclusion body myositis although the upstream events are different [6, 46, 47]. The same mechanism could also be involved in the muscle degeneration and protein aggregation seen in advanced cases of Laing distal myopathy.

In a recent investigation of the molecular background of the mouse mutant ariel a recessive missense mutation, L342Q, in the motor domain of Myh4 was found to cause a myofibrillar myopathy-like phenotype with protein aggregates in fast MyHC IIb fibers [33]. The mutant protein formed also aggregates in COS7 cells and did not incorporate into thick filaments of $\mathrm{C} 2 \mathrm{C} 12$ cells. In ariel heterozygotes, which showed no weakness or aggregates, the level of mutant protein was only $7 \%$, indicating efficient degradation of the defective protein prohibiting protein aggregation. MYH4 is not expressed in human limb muscle. However, mRNA but not protein has been identified in human masseter muscle [30]. A functional equivalent of mouse MyHC IIb is MyHC IIx (MYHI) in humans. So far no disease has been associated with human MYH1 mutations. Protein aggregation with features similar to those in myofibrillar myopathy and in the ariel mouse was identified in one patient with a mutation in the rod region of MyHC I (MYH7) mutation [77].

\section{MyHC IIa null mutations}

The selective muscle involvement of certain muscles with fatty infiltration and loss of type $2 \mathrm{~A}$ muscle fibers with interstitial fatty infiltration in patients with MyHC IIa null myopathy indicate that complete loss of one adult $\mathrm{MyHC}$ cannot be compensated for by other MyHC isoforms [70]. This is further supported by studies on strains of mice null for different $\mathrm{MyHC}$ isoforms indicating that different isoforms of MyHC are functionally unique and cannot substitute for one another $[1,2,60]$. Mice MyHC IIb or IId null strains are viable but exhibit growth and muscle defects with significant decreases in body mass and mean muscle mass. Although both strains showed evidence of skeletal muscle pathology, the extent and the pattern of affected muscles did not correlate with the abundance and distribution of the two MyHC isoforms in normal mice. Together these observations indicate that MyHC isoforms impose unique structural and functional roles and support the hypothesis that $\mathrm{MyHC}$ isoforms are unable to replace one another.

\section{Mutations in the LMM region of slow/ $\beta$-cardiac MyHC}

Mutations in the middle and distal part of the slow/ $\beta$-cardiac MyHC rod (LMM) region have been associated with several distinct morphological and clinical phenotypes depending on the location of the mutated residue. The assembly of MyHC filaments involves both the proper folding of $\alpha$-helices into coiled-coils, and the assembly of these coiled-coils into filaments. Defects in any of these steps, caused by mutations, may result in improper filament formation leading to pathological conditions. Coiled-coils are two-stranded protein motifs, where each strand is an $\alpha$-helix with seven-residue repeats $(a-b-c-d-e-f-$ g) (Fig. 15). This heptad repeat generally has apolar residues at the $a$ and $d$ positions. When the two $\alpha$-helical strands wrap around one another, the $a$ and $d$ positions are internalized and stabilize the structure. Positions $b, c, e, f, g$ are exposed on the surface of the protein, where the side chains are available to interact with other proteins, and they may also form intra- and interchain associations that can further stabilize the structure.

Mutations in the LMM region can affect the ability of the protein to form stable and functional thick filaments, based on the amino acid change, the position in the heptad repeat motif and the location in the LMM. Missense mutations associated with myosin storage myopathy (L1793P, R1845W, E1883K and H1901L) are located within or closed to the 29-residue assembly competence domain, in the $\mathrm{C}$-terminus coiled-coil rod region of $\mathrm{MyHC}$, which is known to be critical for the proper assembly of sarcomeric myosin rod filaments [67]. These mutated residues are located either in the outer $b$ or $f$ position, where the side chains are available to interact with other myosin dimers or other proteins, or in the $d$ position that stabilize the structure of the protein. Mutations at outer positions may cause improper filament formation through disturbed interaction with other myosin dimers and thereby perturb thick filament assembly.

A disturbed interaction with other sarcomeric proteins such as titin, myosin-binding proteins (MyBP) $\mathrm{C}$ and $\mathrm{H}$, M-protein or myomesin 1, may also be considered. In this context it is of interest to note that one patient with a mutation in the rod region of MyHC I showed cytoplasmic bodies [77], a type of protein aggregates that are otherwise typically associated with A-band titin (TTN) mutations [48].

The aberrant accumulations of myosin in the muscle fibers of affected individuals with myosin storage myopathy might be due to improper incorporation of mutated myosin into thick filaments or disassembly of the filaments resulting in accumulation of mutant protein between the 

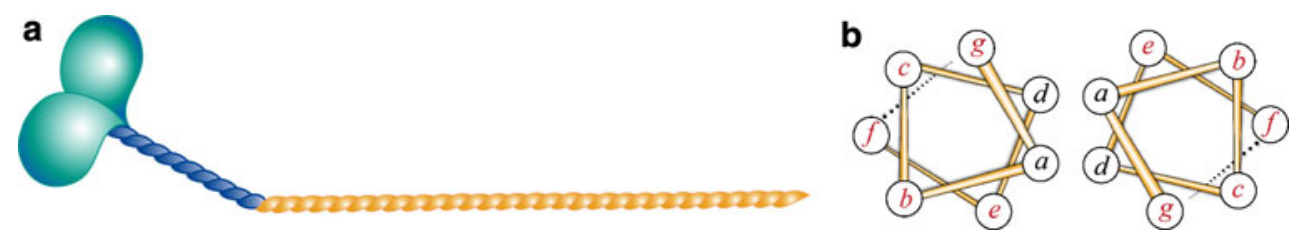

Fig. 15 The assembly of MyHC LMM rod domain into coiled-coil $\alpha$-helices. The heptad repeat motif forms the structural basis for the LMM coiled-coil dimer. The cross-section of the double $\alpha$-helix

myofibrils and beneath the sarcolemma. The observation that some of the accumulated myosin appears to be ubiquitinated indicates that it is marked to be degraded through the proteasomal pathway [17]. The accumulation may be due to insufficient degradation. It is noteworthy that the inclusion bodies are not labeled by p62, which is otherwise common in protein aggregate diseases [86].

Several in vitro studies have been performed to investigate molecular mechanisms involved in the pathogenesis of diseases caused by mutations in the rod region of muscle MyHC. Biochemical and biophysical characterization of the effects of the myosin storage myopathy mutations in the LMM region have suggested adverse effects of the mutations in the ability of the protein to form stable and functional thick filaments [4]. However, analyses of different mutations demonstrated that each mutation has a unique effect on the biochemical and biophysical properties of the LMM [4]. The pathogenic mechanisms of the $\mathrm{R} 1500 \mathrm{P}$ and L1706P causing Laing early-onset distal myopathy have been investigated by biochemical assays and in different cellular systems [5, 12]. By co-expression of wild-type and mutant proteins in non-muscle COS-7 cells, in the $\mathrm{C} 2 \mathrm{C} 12$ mouse muscle cell line and in neonatal rat ventricular myocytes, dominant adverse effects could be demonstrated including formation of myosin aggregates [12]. Generation of transgenic C. elegans indicated that the proline mutations did not affect the thick filament formation or muscle force generation but myosin aggregates were identified in the R1500P mutants [12].

It is still unclear why Laing distal myopathy and myosin storage myopathy are associated with different muscle pathologies. Myosin storage myopathy mutations are located in exons 37-40 in the LMM region of slow/ $\beta$ cardiac MyHC within or close to the assembly competence domain, which is crucial for proper filament assembly. Consequently, mutations in this region may cause defective integration of dimers into the thick filament leading to accumulation of unassembled MyHC. In contrast, mutations associated with Laing distal myopathy that are situated at distance from the assembly competence domain might cause other effects on the thick filament structure and function leading to different pathology. coiled-coil with the heptad repeat sequences. While the residues at positions $a$ and $d$ form the core of the $\alpha$-helix, the residues at positions $b, c, e, f$ and $g$ are located at the outer region of the coiled-coil

\section{Conclusions}

Further work is needed to get insight into the mechanisms governing the cardiac and/or skeletal muscle involvement as well as the pathogenesis leading to protein aggregation in some of the myosin myopathies. For this purpose and for classification of the diseases, which may show clinical overlap, it is essential to perform morphological investigations. Based on correlations between genotype and muscle phenotype in humans, the use of animal models in combination with in vitro studies will allow investigation of the disease mechanisms and clarify the functional impact of mutations affecting different isoforms and different domains of the MyHC.

Acknowledgments This work was supported by the Swedish Research Council Proj. No. 07122 and 20628.

Open Access This article is distributed under the terms of the Creative Commons Attribution License which permits any use, distribution, and reproduction in any medium, provided the original author(s) and the source are credited.

\section{References}

1. Acakpo-Satchivi LJ, Edelmann W, Sartorius C, Lu BD, Wahr PA, Watkins SC, Metzger JM, Leinwand L, Kucherlapati R (1997) Growth and muscle defects in mice lacking adult myosin heavy chain genes. J Cell Biol 139:1219-1229

2. Allen DL, Harrison BC, Leinwand LA (2000) Inactivation of myosin heavy chain genes in the mouse: diverse and unexpected phenotypes. Microsc Res Tech 50:492-499

3. Alvarado DM, Buchan JG, Gurnett CA, Dobbs MB (2011) Exome sequencing identifies an MYH3 mutation in a family with distal arthrogryposis type 1. J Bone Joint Surg Am 93:1045-1050

4. Armel TZ, Leinwand LA (2009) Mutations in the beta-myosin rod cause myosin storage myopathy via multiple mechanisms. Proc Natl Acad Sci USA 106:6291-6296

5. Armel TZ, Leinwand LA (2010) Mutations at the same amino acid in myosin that cause either skeletal or cardiac myopathy have distinct molecular phenotypes. J Mol Cell Cardiol 48: 1007-1013

6. Askanas V, Engel WK (2011) Sporadic inclusion-body myositis: conformational multifactorial ageing-related degenerative muscle disease associated with proteasomal and lysosomal inhibition, 
endoplasmic reticulum stress, and accumulation of amyloid-beta42 oligomers and phosphorylated tau. Presse Med 40:e219-e235

7. Balduini CL, Pecci A, Savoia A (2011) Recent advances in the understanding and management of MYH9-related inherited thrombocytopenias. Br J Haematol 154:161-174

8. Bamshad M, Jorde LB, Carey JC (1996) A revised and extended classification of the distal arthrogryposes. Am J Med Genet 65:277-281

9. Barohn RJ, Brumback RA, Mendell JR (1994) Hyaline body myopathy. Neuromuscul Disord 4:257-262

10. Bohlega S, Abu-Amero SN, Wakil SM, Carroll P, Al-Amr R, Lach B, Al-Sayed Y, Cupler EJ, Meyer BF (2004) Mutation of the slow myosin heavy chain rod domain underlies hyaline body myopathy. Neurology 62:1518-1521

11. Bohlega S, Lach B, Meyer BF, Al Said Y, Kambouris M, Al Homsi M, Cupler EJ (2003) Autosomal dominant hyaline body myopathy: clinical variability and pathologic findings. Neurology 61:1519-1523

12. Buvoli M, Buvoli A, Leinwand LA (2012) Effects of pathogenic proline mutations on Myosin assembly. J Mol Biol 415:807-818

13. Cancilla PA, Kalayanaraman K, Verity MA, Munsat T, Pearson CM (1971) Familial myopathy with probable lysis of myofibrils in type I fibers. Neurology 21:579-585

14. Carniel E, Taylor MR, Sinagra G, Di Lenarda A, Ku L, Fain PR, Boucek MM, Cavanaugh J, Miocic S, Slavov D, Graw SL, Feiger J, Zhu XZ, Dao D, Ferguson DA, Bristow MR, Mestroni L (2005) Alpha-myosin heavy chain: a sarcomeric gene associated with dilated and hypertrophic phenotypes of cardiomyopathy. Circulation 112:54-59

15. Ceuterick C, Martin JJ, Martens C (1993) Hyaline bodies in skeletal muscle of a patient with a mild chronic nonprogressive congenital myopathy. Clin Neuropathol 12:79-83

16. Ching YH, Ghosh TK, Cross SJ, Packham EA, Honeyman L, Loughna S, Robinson TE, Dearlove AM, Ribas G, Bonser AJ, Thomas NR, Scotter AJ, Caves LS, Tyrrell GP, Newbury-Ecob RA, Munnich A, Bonnet D, Brook JD (2005) Mutation in myosin heavy chain 6 causes atrial septal defect. Nat Genet 37:423-428

17. Ciechanover A (2012) Intracellular protein degradation: from a vague idea thru the lysosome and the ubiquitin-proteasome system and onto human diseases and drug targeting. Biochim Biophys Acta 1824:3-13

18. D'Agostino C, Nogalska A, Engel WK, Askanas V (2011) In sporadic inclusion body myositis muscle fibres TDP-43-positive inclusions are less frequent and robust than p62 inclusions, and are not associated with paired helical filaments. Neuropathol Appl Neurobiol 37:315-320

19. Darin N, Kyllerman M, Wahlstrom J, Martinsson T, Oldfors A (1998) Autosomal dominant myopathy with congenital joint contractures, ophthalmoplegia, and rimmed vacuoles. Ann Neurol 44:242-248

20. Darin N, Tajsharghi H, Ostman-Smith I, Gilljam T, Oldfors A (2007) New skeletal myopathy and cardiomyopathy associated with a missense mutation in MYH7. Neurology 68:2041-2042

21. Dubourg O, Maisonobe T, Behin A, Suominen T, Raheem O, Penttila S, Parton M, Eymard B, Dahl A, Udd B (2011) A novel MYH7 mutation occurring independently in French and Norwegian Laing distal myopathy families and de novo in one Finnish patient. J Neurol 258:1157-1163

22. Dye DE, Azzarelli B, Goebel HH, Laing NG (2006) Novel slowskeletal myosin (MYH7) mutation in the original myosin storage myopathy kindred. Neuromuscul Disord 16:357-360

23. Fananapazir L, Dalakas MC, Cyran F, Cohn G, Epstein ND (1993) Missense mutations in the beta-myosin heavy-chain gene cause central core disease in hypertrophic cardiomyopathy. Proc Natl Acad Sci USA 90:3993-3997
24. Feghali R, Leinwand LA (1989) Molecular genetic characterization of a developmentally regulated human perinatal myosin heavy chain. J Cell Biol 108:1791-1797

25. Geisterfer-Lowrance AA, Kass S, Tanigawa G, Vosberg HP, McKenna W, Seidman CE, Seidman JG (1990) A molecular basis for familial hypertrophic cardiomyopathy: a beta cardiac myosin heavy chain gene missense mutation. Cell 62:999-1006

26. Hall JG, Reed SD, Greene G (1982) The distal arthrogryposes: delineation of new entities-review and nosologic discussion. Am J Med Genet 11:185-239

27. Han KH, Lee H, Kang HG, Moon KC, Lee JH, Park YS, Ha IS, Ahn HS, Choi Y, Cheong HI (2011) Renal manifestations of patients with MYH9-related disorders. Pediatr Nephrol 26: $549-555$

28. Heath KE, Campos-Barros A, Toren A, Rozenfeld-Granot G, Carlsson LE, Savige J, Denison JC, Gregory MC, White JG, Barker DF, Greinacher A, Epstein CJ, Glucksman MJ, Martignetti JA (2001) Nonmuscle myosin heavy chain IIA mutations define a spectrum of autosomal dominant macrothrombocytopenias: May-Hegglin anomaly and Fechtner, Sebastian, Epstein, and Alport-like syndromes. Am J Hum Genet 69:1033-1045

29. Homayoun H, Khavandgar S, Hoover JM, Mohsen AW, Vockley J, Lacomis D, Clemens PR (2011) Novel mutation in MYH7 gene associated with distal myopathy and cardiomyopathy. Neuromuscul Disord 21:219-222

30. Horton MJ, Brandon CA, Morris TJ, Braun TW, Yaw KM, Sciote JJ (2001) Abundant expression of myosin heavy-chain IIB RNA in a subset of human masseter muscle fibres. Arch Oral Biol 46:1039-1050

31. Karsch-Mizrachi I, Travis M, Blau H, Leinwand LA (1989) Expression and DNA sequence analysis of a human embryonic skeletal muscle myosin heavy chain gene. Nucleic Acids Res 17:6167-6179

32. Kiphuth IC, Neuen-Jacob E, Struffert T, Wehner M, Wallefeld W, Laing N, Schroder R (2010) Myosin storage myopathy: a rare subtype of protein aggregate myopathies. Fortschr Neurol Psychiatr 78:219-222

33. Kurapati R, McKenna C, Lindqvist J, Williams D, Simon M, LeProust E, Baker J, Cheeseman M, Carroll N, Denny P, Laval S, Lochmuller H, Ochala J, Blanco G (2012) Myofibrillar myopathy caused by a mutation in the motor domain of mouse MyHC IIb. Hum Mol Genet 21:1706-1724

34. Laing NG, Ceuterick-de Groote C, Dye DE, Liyanage K, Duff RM, Dubois B, Robberecht W, Sciot R, Martin JJ, Goebel HH (2005) Myosin storage myopathy: slow skeletal myosin (MYH7) mutation in two isolated cases. Neurology 64:527-529

35. Laing NG, Laing BA, Meredith C, Wilton SD, Robbins P, Honeyman K, Dorosz S, Kozman H, Mastaglia FL, Kakulas BA (1995) Autosomal dominant distal myopathy: linkage to chromosome 14. Am J Hum Genet 56:422-427

36. Lamont PJ, Udd B, Mastaglia FL, de Visser M, Hedera P, Voit T, Bridges LR, Fabian V, Rozemuller A, Laing NG (2006) Laing early onset distal myopathy: slow myosin defect with variable abnormalities on muscle biopsy. J Neurol Neurosurg Psychiatry 77:208-215

37. Larsson L (2008) Acute quadriplegic myopathy: an acquired "myosinopathy". Adv Exp Med Biol 642:92-98

38. Li M, Lionikas A, Yu F, Tajsharghi H, Oldfors A, Larsson L (2006) Muscle cell and motor protein function in patients with a IIa myosin missense mutation (Glu-706 to Lys). Neuromuscul Disord 16:782-791

39. Martinsson T, Darin N, Kyllerman M, Oldfors A, Hallberg B, Wahlstrom J (1999) Dominant hereditary inclusion-body myopathy gene (IBM3) maps to chromosome region 17p13.1. Am J Hum Genet 64:1420-1426 
40. Martinsson T, Oldfors A, Darin N, Berg K, Tajsharghi H, Kyllerman M, Wahlström J (2000) Autosomal dominant myopathy: missense mutation (Glu-706 to Lys) in the myosin heavy chain IIa gene. Proc Natl Acad Sci USA 97:14614-14619

41. Mastaglia FL, Phillips BA, Cala LA, Meredith C, Egli S, Akkari PA, Laing NG (2002) Early onset chromosome 14-linked distal myopathy (Laing). Neuromuscul Disord 12:350-357

42. Masuzugawa S, Kuzuhara S, Narita Y, Naito Y, Taniguchi A, Ibi $\mathrm{T}$ (1997) Autosomal dominant hyaline body myopathy presenting as scapuloperoneal syndrome: clinical features and muscle pathology. Neurology 48:253-257

43. Meredith C, Herrmann R, Parry C, Liyanage K, Dye DE, Durling HJ, Duff RM, Beckman K, De Visser M, Van Der Graaff MM, Hedera P, Fink JK, Petty EM, Lamont P, Fabian V, Bridges L, Voit T, Mastaglia FL, Laing NG (2004) Mutations in the slow skeletal muscle fiber myosin myosin chain gene (MYH7) cause Laing early-onset distal myopathy (MPD1). Am J Hum Genet 75:703-708

44. Muelas N, Hackman P, Luque H, Garces-Sanchez M, Azorin I, Suominen T, Sevilla T, Mayordomo F, Gomez L, Marti P, Maria Millan J, Udd B, Vilchez JJ (2010) MYH7 gene tail mutation causing myopathic profiles beyond Laing distal myopathy. Neurology 75:732-741

45. Muelas N, Hackman $P$, Luque $H$, Suominen $T$, Espinos C, Garces-Sanchez M, Sevilla T, Azorin I, Millan J, Udd B, Vilchez J (2012) Spanish MYH7 founder mutation of Italian ancestry causing a large cluster of Laing myopathy patients. Clin Genet 81:491-494

46. Needham M, Mastaglia FL (2007) Inclusion body myositis: current pathogenetic concepts and diagnostic and therapeutic approaches. Lancet Neurol 6:620-631

47. Nogalska A, Terracciano C, D'Agostino C, King Engel W, Askanas V (2009) p62/SQSTM1 is overexpressed and prominently accumulated in inclusions of sporadic inclusion-body myositis muscle fibers, and can help differentiating it from polymyositis and dermatomyositis. Acta Neuropathol 118:407-413

48. Ohlsson M, Hedberg C, Bradvik B, Lindberg C, Tajsharghi H, Danielsson O, Melberg A, Udd B, Martinsson T, Oldfors A (2012) Hereditary myopathy with early respiratory failure associated with a mutation in A-band titin. Brain 135(Pt 6): $1682-1694$

49. Oldfors A (2007) Hereditary myosin myopathies. Neuromuscul Disord 17:355-367

50. Oldfors A, Lamont PJ (2008) Thick filament diseases. Adv Exp Med Biol 642:78-91

51. Ortolano S, Tarrio R, Blanco-Arias $\mathrm{P}$, Teijeira S, RodriguezTrelles F, Garcia-Murias M, Delague V, Levy N, Fernandez JM, Quintans B, Millan BS, Carracedo A, Navarro C, Sobrido MJ (2011) A novel MYH7 mutation links congenital fiber type disproportion and myosin storage myopathy. Neuromuscul Disord 21:254-262

52. Osterlund C, Thornell LE, Eriksson PO (2011) Differences in fibre type composition between human masseter and biceps muscles in young and adults reveal unique masseter fibre type growth pattern. Anat Rec (Hoboken) 294:1158-1169

53. Overeem S, Schelhaas HJ, Blijham PJ, Grootscholten MI, Ter Laak HJ, Timmermans J, van den Wijngaard A, Zwarts MJ (2007) Symptomatic distal myopathy with cardiomyopathy due to a MYH7 mutation. Neuromuscul Disord 17:490-493

54. Pedrosa-Domellöf F, Holmgren Y, Lucas CA, Hoh JF, Thornell LE (2000) Human extraocular muscles: unique pattern of myosin heavy chain expression during myotube formation. Invest Ophthalmol Vis Sci 41:1608-1616

55. Pegoraro E, Gavassini BF, Borsato C, Melacini P, Vianello A, Stramare R, Cenacchi G, Angelini C (2007) MYH7 gene mutation in myosin storage myopathy and scapulo-peroneal myopathy. Neuromuscul Disord 17:321-329

56. Rayment I, Holden HM, Whittaker M, Yohn CB, Lorenz M, Holmes KC, Milligan RA (1993) Structure of the actin-myosin complex and its implications for muscle contraction. Science 261:58-65

57. Ruppel KM, Spudich JA (1996) Structure-function analysis of the motor domain of myosin. Annu Rev Cell Dev Biol 12: 543-573

58. Ruppel KM, Spudich JA (1996) Structure-function studies of the myosin motor domain: importance of the $50-\mathrm{kDa}$ cleft. Mol Biol Cell 7:1123-1136

59. Sahgal V, Sahgal S (1977) A new congenital myopathy: a morphological, cytochemical and histochemical study. Acta Neuropathol (Berl) 37:225-230

60. Sartorius CA, Lu BD, Acakpo-Satchivi L, Jacobsen RP, Byrnes WC, Leinwand LA (1998) Myosin heavy chains IIa and IId are functionally distinct in the mouse. J Cell Biol 141:943-953

61. Schiaffino S (2010) Fibre types in skeletal muscle: a personal account. Acta Physiol (Oxf) 199:451-463

62. Schiaffino S, Reggiani C (1994) Myosin isoforms in mammalian skeletal muscle. J Appl Physiol 77:493-501

63. Schiaffino S, Reggiani C (1996) Molecular diversity of myofibrillar proteins: gene regulation and functional significance. Physiol Rev 76:371-423

64. Sellers JR (2000) Myosins: a diverse superfamily. Biochim Biophys Acta 1496:3-22

65. Shingde MV, Spring PJ, Maxwell A, Wills EJ, Harper CG, Dye DE, Laing NG, North KN (2006) Myosin storage (hyaline body) myopathy: a case report. Neuromuscul Disord 16:882-886

66. Smerdu V, Karsch-Mizrachi I, Campione M, Leinwand L, Schiaffino S (1994) Type IIx myosin heavy chain transcripts are expressed in type IIb fibers of human skeletal muscle. Am J Physiol 267:C1723-C1728

67. Sohn RL, Vikstrom KL, Strauss M, Cohen C, Szent-Gyorgyi AG, Leinwand LA (1997) A 29 residue region of the sarcomeric myosin rod is necessary for filament formation. J Mol Biol 266:317-330

68. Stalpers X, Verrips A, Braakhekke J, Lammens M, van den Wijngaard A, Mostert A (2011) Scoliosis surgery in a patient with "de novo" myosin storage myopathy. Neuromuscul Disord $21: 812-815$

69. Sunnerhagen KS, Darin N, Tasjharghi H, Oldfors A (2004) The effects of endurance training in persons with a hereditary myosin myopathy. Acta Neurol Scand 110:80-86

70. Tajsharghi H, Hilton-Jones D, Raheem O, Saukkonen AM, Oldfors A, Udd B (2010) Human disease caused by loss of fast IIa myosin heavy chain due to recessive MYH2 mutations. Brain 133:1451-1459

71. Tajsharghi H, Kimber E, Kroksmark AK, Jerre R, Tulinius M, Oldfors A (2008) Embryonic myosin heavy-chain mutations cause distal arthrogryposis and developmental myosin myopathy that persists postnatally. Arch Neurol 65:1083-1090

72. Tajsharghi H, Oldfors A, Macleod DP, Swash M (2007) Homozygous mutation in $\mathrm{MYH7}$ in myosin storage myopathy and cardiomyopathy. Neurology 68:962

73. Tajsharghi H, Pilon M, Oldfors A (2005) A Caenorhabditis elegans model of the myosin heavy chain IIa E706K mutation. Ann Neurol 58:442-448

74. Tajsharghi H, Stibrant Sunnerhagen K, Darin N, Kyllerman M, Oldfors A (2004) Induced shift in myosin heavy chain expression in myosin myopathy by endurance training. J Neurol 251: 179-183

75. Tajsharghi H, Thornell LE, Darin N, Martinsson T, Kyllerman M, Wahlstrom J, Oldfors A (2002) Myosin heavy chain IIa gene 
mutation E706 $\mathrm{K}$ is pathogenic and its expression increases with age. Neurology 58:780-786

76. Tajsharghi H, Thornell LE, Lindberg C, Lindvall B, Henriksson KG, Oldfors A (2003) Myosin storage myopathy associated with a heterozygous missense mutation in MYH7. Ann Neurol 54:494-500

77. Tasca G, Ricci E, Penttila S, Monforte M, Giglio V, Ottaviani P, Camastra G, Silvestri G, Udd B (2012) New phenotype and pathology features in MYH7-related distal myopathy. Neuromuscul Disord 22:640-647

78. Toydemir RM, Chen H, Proud VK, Martin R, van Bokhoven H, Hamel BC, Tuerlings JH, Stratakis CA, Jorde LB, Bamshad MJ (2006) Trismus-pseudocamptodactyly syndrome is caused by recurrent mutation of MYH8. Am J Med Genet A 140:2387-2393

79. Toydemir RM, Rutherford A, Whitby FG, Jorde LB, Carey JC, Bamshad MJ (2006) Mutations in embryonic myosin heavy chain (MYH3) cause Freeman-Sheldon syndrome and Sheldon-Hall syndrome. Nat Genet 38:561-565

80. Udd B (2009) 165th ENMC International Workshop: distal myopathies 6-8th February 2009 Naarden, The Netherlands. Neuromuscul Disord 19:429-438

81. Uro-Coste E, Arne-Bes MC, Pellissier JF, Richard P, Levade T, Heitz F, Figarella-Branger D, Delisle MB (2009) Striking phenotypic variability in two familial cases of myosin storage myopathy with a MYH7 Leu1793pro mutation. Neuromuscul Disord 19:163-166
82. Veugelers $M$, Bressan $M$, McDermott DA, Weremowicz S, Morton CC, Mabry CC, Lefaivre JF, Zunamon A, Destree A, Chaudron JM, Basson CT (2004) Mutation of perinatal myosin heavy chain associated with a Carney complex variant. N Engl J Med 351:460-469

83. Voit T, Kutz P, Leube B, Neuen-Jacob E, Schroder JM, Cavallotti D, Vaccario ML, Schaper J, Broich P, Cohn R, Baethmann M, Gohlich-Ratmann G, Scoppetta C, Herrmann R (2001) Autosomal dominant distal myopathy: further evidence of a chromosome 14 locus. Neuromuscul Disord 11:11-19

84. Weiss A, Leinwand LA (1996) The mammalian myosin heavy chain gene family. Annu Rev Cell Dev Biol 12:417-439

85. Weiss A, McDonough D, Wertman B, Acakpo-Satchivi L, Montgomery K, Kucherlapati R, Leinwand L, Krauter K (1999) Organization of human and mouse skeletal myosin heavy chain gene clusters is highly conserved. Proc Natl Acad Sci USA 96:2958-2963

86. Zatloukal K, Stumptner C, Fuchsbichler A, Heid H, Schnoelzer M, Kenner L, Kleinert R, Prinz M, Aguzzi A, Denk H (2002) p62 Is a common component of cytoplasmic inclusions in protein aggregation diseases. Am J Pathol 160:255-263

87. Zeng W, Conibear PB, Dickens JL, Cowie RA, Wakelin S, Malnasi-Csizmadia A, Bagshaw CR (2004) Dynamics of actomyosin interactions in relation to the cross-bridge cycle. Phil Trans R Soc B 359:1843-1855 